\title{
OJS

\section{O TRABALHO DE CAMPO NÃO É SÓ LAZER: UM RECURSO METODOLÓGICO IMPRESCINDÍVEL NO PROCESSO DE ENSINO-APRENDIZAGEM EM GEOGRAFIA}

\author{
Ricardo Chaves de Farias ${ }^{1}$, Alcinéia de Souza Silva² \\ ${ }^{1}$ Mestre em Geografia pela Universidade de Brasília (UnB) e Professor de Geografia na Rede Privada de Ensino do \\ Distrito Federal - DF. E-mail: ricardochaves@outlook.com; http://orcid.org/0000-0002-2044-9097. \\ ${ }^{2}$ Mestra e Doutoranda em Geografia pela Universidade de Brasília (UnB) e Professora na Rede Pública de Ensino no \\ município de Formosa-GO. E-mail: alcineias32@gmail.com; http://orcid.org/0000-0002-8975-5295.
}

Artigo recebido em 27/07/2020 e aceito em 01/03/2021

\begin{abstract}
RESUMO: Partindo da sistematização de um método para o desenvolvimento do trabalho de campo na Educação Básica, o artigo discorre sobre as potencialidades desse recurso metodológico no processo de ensino-aprendizagem em Geografia. Para tanto, a discussão teórica de cunho crítico e a observação participante em um trabalho realizado no município de Pirenópolis-GO constituem-se os procedimentos metodológicos empregados nesse estudo. Os resultados explicitam que, fundamentando-se em um método que assegure o desenvolvimento pedagógico dessa prática e em aportes teóricos que favoreçam a compreensão da espacialidade dos fatos/fenômenos, o trabalho de campo constitui-se como um instrumento eficaz na construção de conhecimentos geográficos. Destaca-se que sua finalidade é educativa e viabiliza o raciocínio geográfico por meio de atividades práticas e mentais frente aos objetos/fenômenos estudados.
\end{abstract}

Palavras-chave: Geografia Escolar; Método; Trabalho de Campo.

\section{FIELDWORK IS NOT JUST LEISURE: AN UNIQUE METHODOLOGICAL RESOURCE IN THE TEACHING-LEARNING PROCESS IN GEOGRAPHY}

\begin{abstract}
Starting from the systematization of a method for the development of fieldwork in Basic Education, the article discusses the potential of this methodological resource in the teaching-learning process in Geography. For this purpose, the theoretical discussion of a critical nature and participant observation in a work carried out in the municipality of Pirenópolis-GO constitute the methodological procedures employed in this study. The results show that, based on a method that ensures the pedagogical development of this practice and on theoretical contributions that favor the understanding of the spatiality of facts/phenomena, fieldwork is an effective instrument in the construction of geographical knowledge. It is noteworthy that its purpose is educational and enables geographic reasoning through practical and mental activities in relation to the objects / phenomena studied.
\end{abstract}

Keywords: School Geography; Method; Fieldwork. 


\section{INTRODUÇÃO}

O presente artigo discute um importante objeto para o fazer geográfico, o trabalho de campo. Trata-se de uma prática secular, além de um recurso indispensável para o trabalho do geógrafo e do professor de Geografia, em razão de suas potencialidades na construção de conhecimentos. De modo específico, a discussão empreendida neste trabalho se apresenta como uma oportunidade de trazer à tona o potencial deste recurso metodológico que possui alto valor pedagógico e que, embora em algumas práticas não seja realizado de forma adequada, é utilizado por muitos docentes ao redor do mundo.

Cumpre dizer que tal discussão ocorre em tempos de reformas educacionais no Brasil, como a reforma do Ensino Médio (instituída pela Lei n⿳ 13.415, de 16 de fevereiro de 2017), em que a Geografia é duramente atacada. Instituiu-se nessa política de bases e perspectivas neoliberais, a desobrigatoriedade do ensino de Geografia ao longo desta etapa de ensino. Na reforma, reduziu-se a importância da Geografia na formação dos estudantes, ao serem diminuídos os seus tempos e espaços curriculares, desvalorizando seus aportes teóricos e metodológicos.

Nesse contexto de ataques e desmantelamentos educacionais, entendemos que ser professor dessa disciplina na Educação Básica se torna, mais do que nunca, um ato de resistência. Dessa forma, buscamos enriquecer o debate acerca da importância e imprescindibilidade da Geografia Escolar no cenário contemporâneo, pautados em teorizações e evidências empíricas que expressam o valor da ciência geográfica na escola, especialmente no bojo de suas questões metodológicas/didáticopedagógicas e, consequentemente, na formação dos estudantes.

É válido destacar que durante o período político da Ditadura Militar no Brasil, práticas cujos métodos de ensino pautavam-se pela imersão na realidade como um meio de descobertas (PONTUSCHKA, 2004), foram proibidas no país. Essa recordação torna-se mais um elemento para fomentar o debate acerca das potencialidades do trabalho de campo e justificar a produção desse texto, pois acreditamos que em tempos de ascensão de governos antidemocráticos cujos projetos buscam censurar e/ou reprimir o professor, compostos por políticas que restringem o acesso ao conhecimento geográfico, valorizar práticas que potencializam a construção de conhecimentos e o desenvolvimento da autonomia e do pensamento crítico (e geográfico) do estudante são cruciais ao desenvolvimento e fortalecimento da Geografia Escolar.

Diante dessas considerações, o presente artigo discorre sobre as potencialidades do trabalho de campo no processo de ensino-aprendizagem em Geografia, à luz da descrição de uma prática realizada no município de Pirenópolis-GO com estudantes do $6^{\circ}$ ano - Anos Finais do Ensino 
Fundamental - de uma escola do Distrito Federal (DF). Para tanto, as metodologias utilizadas foram a discussão teórica de cunho crítico e a observação participante. Em termos estruturais, na primeira seção do trabalho tratamos da Geografia Escolar, delineando sua(s) concepção(ões) e funções, sobretudo na contemporaneidade. Buscamos, com isso, elucidar as especificidades da Geografia enquanto componente curricular e suas questões metodológicas. Assim, o quê, para quê e por quê ensinar Geografia são assuntos tratados nesta parte do trabalho, juntamente com a discussão sobre o trabalho de campo envolvendo concepções, método e valor pedagógico. Na segunda seção, descrevemos e discutimos a experiência pedagógica desenvolvida em Pirenópolis-GO, relacionandoa com o método apresentado e as questões teorizadas. Desvela-se, com isso, as capacidades do trabalho de campo nas aulas de Geografia, uma vez que, por meio das atividades prática e cognitiva dos estudantes, contribui para seu desenvolvimento intelectual e exercício da cidadania pela construção de conhecimentos geográficos.

\section{GEOGRAFIA ESCOLAR: CONCEPÇÕES, NATUREZA, FINALIDADES E QUESTÕES METODOLÓGICAS}

Em primeiro lugar, torna-se necessária a compreensão do que é a Geografia Escolar para, assim, discutirmos acerca de sua natureza, finalidades e metodologias. A Geografia Escolar é decorrente das práticas e teorizações próprias da escola, pois nesse espaço o conhecimento acadêmico é modificado de forma que se converte em um saber específico, objeto de ensino e aprendizagem, direcionado ao cumprimento das finalidades atribuídas à educação escolar. Apesar da afirmação apresentada, não queremos dizer que a Geografia Escolar é uma simplificação do conhecimento geográfico produzido na universidade, mas afirmamos que a escola possui elementos próprios que se sustentam da parte acadêmica e se aliam aos elementos pedagógicos para a construção de conhecimentos.

Essa compreensão se aproxima da discussão empreendida por Callai (2013, p. 43), quando afirma que "a Geografia escolar é um conhecimento diferente da Geografia acadêmica. Ela é, pois, uma criação particular e original da escola, que responde às finalidades sociais que lhe são próprias", com metodologias, linguagem e aportes teóricos específicos. Sendo assim, a Geografia, enquanto ciência, responde aos problemas produzidos pelos homens na produção social do espaço; enquanto disciplina escolar, a Geografia possibilita ao aluno a compreensão e transformação desse espaço (CALLAI, 2010). 
Ao compreendermos que a Geografia Escolar é o conhecimento geográfico veiculado, trabalhado e ensinado em sala de aula, como defende Cavalcanti (2012b), e ao entendermos que o ensino de Geografia tem o papel de prover meios para que os alunos possam compreender o papel do espaço nas práticas sociais e destas na configuração do espaço (CAVALCANTI, 1998), justificamos a presença e a importância da Geografia no currículo da Educação Básica, bem como a importância do desenvolvimento de metodologias que favoreçam a aprendizagem geográfica. Isso porque a compreensão das dinâmicas descritas anteriormente colabora com a formação do senso crítico e da cidadania, de modo que, para essa situação, faz-se necessário despertar a autonomia dos estudantes a partir de uma correlação entre sujeito, tempo e espaço (FIALHO, DOS SANTOS MACHADO e DE SALES, 2014).

O preparo do estudante para o exercício da cidadania se configura como umas das funções da escola, e a Geografia tem grande contribuição nesse processo, a partir do momento que contribui para a compreensão do mundo pela sua dimensão espacial e participação política ligada à democracia. Esse processo também é mediado pelos professores enquanto principais agentes do processo educativo ao atuarem na seleção de conteúdos e metodologias que possibilitem a organização de ações que viabilizem essa formação (CAVALCANTI, 2012a).

Essa premissa vai ao encontro das colocações de Santos (2007, p. 20), quando destaca que "a cidadania, sem dúvida, se aprende", e alia-se à Geografia a partir do momento que ela atua como instrumento simbólico do sujeito com o mundo, ao possibilitar a leitura e interpretação do espaço e suas nuances. Sobre isso Damiani (2015, p. 50) afirma que "a noção de cidadania envolve o sentido que se tem do lugar e do espaço, já que se trata da materialização das relações de todas as ordens, próximas ou distantes. Conhecer o espaço é conhecer a rede de relações a que se está sujeito, da qual se é sujeito".

A Geografia, portanto, possui uma relevância social e contribui de modo significativo na formação de cidadãos, que nesse trabalho consideramos como "aquele que exerce seu direito a ter direitos, ativa e democraticamente, o que significa exercer seu direito, inclusive, criar novos direitos e ampliar outros" (CAVALCANTI, 2012b, p. 85). Segundo Carvalho Sobrinho (2016, p. 33), “o exercício da cidadania melhor se efetiva quando o sujeito possui o conhecimento sistematicamente elaborado pela sociedade em seu processo histórico, por possibilitar a reflexão da sua própria inserção e organização no espaço”. Para ele,

[...] ao considerar que a educação e o ensino de Geografia têm o potencial de se constituírem instrumentos de emancipação, pode-se inferir que seu potencial para a construção da cidadania está relacionado à construção de conhecimentos, já que esse procedimento é o que 
permitirá o sujeito a compreender a realidade que o cerca (CARVALHO SOBRINHO, 2016, p. 30).

Nessa mesma dimensão, envolvendo a natureza e as finalidades da Geografia enquanto disciplina escolar, Callai (2013) pontua que

[...] a Geografia Escolar é uma matéria curricular que encaminha a compreender o mundo e as pessoas a se entenderem como sujeitos neste mundo, reconhecendo a espacialidade dos fenômenos sociais. [...] Para ler o espaço há que se ter referenciais teóricos, instrumentos metodológicos, conhecer e compreender os conceitos básicos que permitem fazer esta leitura (CALLAI, 2013, p. 40-41).

À luz dessa questão, a escola é o espaço propício para a construção e formação da cidadania, visto que se constitui o lócus onde o estudante adquire os referenciais teóricos imprescindíveis à compreensão do espaço (próximo e/ou distante) e ao alcance da leitura de mundo. Diante dessa importância, quando o Estado questiona a permanência da Geografia no currículo escolar é possível interpretar a intencionalidade dessa ação como uma medida de controle e restrição do pensamento crítico, que, para nós, refere-se a uma política com fins voltados à formação de uma massa de manobra para projetos nefastos e não à formação de cidadãos, uma vez que restringe o acesso a referenciais teóricos imprescindíveis ao desenvolvimento cognitivo e crítico do indivíduo. Ao reduzir o espaço ocupado pela Geografia no currículo do Ensino Médio, por exemplo, seu objetivo é limitar o acesso aos conhecimentos que muito contribuem no desenvolvimento de uma leitura menos ingênua do complexo mundo contemporâneo, por parte do estudante.

Considerando essas peculiaridades e funções da Geografia Escolar, pensar sobre suas questões metodológicas é crucial ao processo de aprendizagem e desenvolvimento do aluno. Assim, a utilização de diferentes estratégias que favoreçam a construção de conhecimentos geográficos tornase elemento importante na leitura crítica e compreensão do mundo e/ou das espacialidades contemporâneas.

Sabe-se que avanço tecnológico e o advento informacional possibilitaram o acesso à informação, permitindo ao aluno novas aprendizagens de forma muito mais dinâmica. Cabe à escola revitalizar-se metodologicamente, de modo a superar as formas tradicionais de ensinar e aprender Geografia e propiciar uma formação geográfica que tenha melhor diálogo com as demandas, os sujeitos, a realidade e os problemas socioespaciais contemporâneos. Nesse sentido, os conteúdos geográficos e os processos didático-pedagógicos são valorosos instrumentos formativos numa perspectiva crítica e cidadã à luz da Geografia Escolar.

Ao escrever sobre o quê ensinar e para quê ensinar Geografia no âmbito escolar, Gonzáles (1999) declara que seus 
[...] contenidos deben ser instrumentos intelectuales que les faciliten la lectura y el análisis de la organización espacial, de los intereses sociales en la misma y los problemas de inestabilidad del medio, donde la acción humana posee una influencia enorme (GONZÁLES 1999, p. 103).

Com base nisso e levando em consideração que o trabalho de campo constitui-se "uma metodologia que engloba a observação, a análise e a interpretação de fenômenos no local e nas condições onde eles ocorrem" (NEVES, 2015, p. 15), concebemo-lo como uma estratégia essencial no processo de ensino-aprendizagem em Geografia, sobretudo no contexto contemporâneo em que a globalização torna mais complexas as questões que envolvem os fatos e fenômenos sociais.

Por ser uma atividade tradicional e bastante presente na Geografia, diferentes autores ao redor do mundo nos apresentam contribuições relevantes para referendar o seu uso na prática escolar. Conforme Kent, Gilbertson e Hunt (1997), o trabalho de campo é uma proposta que possui eficiência para unir prática e teoria em uma abordagem focada no estudante, o que reforça o seu viés ativo.

Ainda sob esse ponto de vista, Smith (2006) nos indica que a atividade também é uma forma intensamente encarnada e experiencial de aprendizagem e ensino, que requer engajamento do estudante com a localidade que ele está conhecendo. Tal abordagem corrobora com a proposta do trabalho de campo retratado no artigo, uma vez que muitos estudantes conheciam apenas o circuito turístico voltado ao consumo na cidade e tiveram a oportunidade de conhecê-la sob outra lente, a geográfica.

Para Castrogiovanni et al (2000, p. 13) o trabalho de campo é "toda atividade oportunizada fora da sala de aula que busque concretizar etapas do conhecimento e/ou desenvolver habilidades em situações concretas perante a observação e participação". Embora essa definição seja simplista, ela nos fornece elementos que caracterizam tal atividade, quais sejam: observar, participar, vivenciar, aprender. Essa metodologia deve constituir-se, de fato, em uma prática educativa que contemple as atividades prática e cognitiva do estudante, favorecendo a construção do conhecimento. Para isso, seu desenvolvimento deve abranger a exploração do seu valor pedagógico e possibilitar aprendizagens significativas a partir do envolvimento do aluno com o fato/fenômeno estudado, de aportes teóricos e metodológicos que facilitem a compreensão desses objetos identificados e percebidos na paisagem e da mediação docente. Não é demais lembrar que o trabalho de campo é uma atividade classificada pelos alunos como estratégia prazerosa de aprendizagem (AMOS e REISS, 2012), o que reforça o seu pensar e fazer metodológico com foco no desenvolvimento intelectual, mas sem perder o prazer em aprender. 
Para que haja a construção de conhecimentos e se efetive a compreensão dos fatos/fenômenos geográficos vivenciados no trabalho de campo, o método ou a sistematização dessa atividade pelo professor é crucial. Partindo de nossas experiências enquanto professores de Geografia que atuam na Educação Básica, procuramos discorrer sobre as potencialidades do trabalho de campo a partir de uma sistematização metodológica que permite viabilizar a aprendizagem geográfica e construir conhecimentos.

Considerando as questões supracitadas, sistematizamos na Tabela 1 um percurso metodológico em que o trabalho de campo é realizado de modo processual, com início, meio e fim. O intuito é provocar reflexões acerca da importância do planejamento, organização e desenvolvimento dessa prática, com foco na aprendizagem e no desenvolvimento do estudante. Tal fato agrega valor ao fazer docente e possibilita que o aluno construa conhecimentos e avance cognitivamente.

Essa sistematização, que envolve procedimentos pré-campo, campo e pós-campo, garante que o professor e os alunos não se percam no decorrer do processo educativo, tampouco deixem de construir os conhecimentos geográficos possibilitados por tal trabalho. As etapas devidamente organizadas contemplam planejamento, estabelecimento de objetivos, definição de conteúdos geográficos, interação dos sujeitos com seus pares e com o objeto estudado, problematização e reflexão acerca desse, relacionamento entre a teoria e a prática/realidade apreciada, mediação docente, enfim, espaços de aprendizagens.

\begin{tabular}{|c|c|c|}
\hline Pré-Campo & $\begin{array}{c}\text { BASICA } \\
\text { Campo }\end{array}$ & Pós-Campo \\
\hline $\begin{array}{l}\text { Planejamento prévio do } \\
\text { professor, envolvendo a } \\
\text { definição de objetivos a serem } \\
\text { alcançados, dos conhecimentos a } \\
\text { serem construídos e do roteiro a } \\
\text { ser seguido; elaboração do } \\
\text { caderno de campo; orientação } \\
\text { aos alunos sobre a atividade a ser } \\
\text { executada; problematização e } \\
\text { promoção de reflexões acerca } \\
\text { dos assuntos que serão } \\
\text { vivenciados em campo. }\end{array}$ & $\begin{array}{l}\text { Possibilitar que o estudante } \\
\text { reflita acerca } \\
\text { fatos/fenômenos visíveis e } \\
\text { invisíveis na paisagem e acerca } \\
\text { dos processos que } \\
\text { atuaram/atuam na produção do } \\
\text { espaço geográfico ao seu redor; } \\
\text { mediar a construção de } \\
\text { conhecimentos, oportunizando } \\
\text { espaços de diálogo e trocas de } \\
\text { experiências a partir das } \\
\text { descobertas e aprendizagens } \\
\text { promovidas; orientar a coleta de } \\
\text { dados e registros no caderno de } \\
\text { campo. }\end{array}$ & $\begin{array}{l}\text { Sistematizar os dados coletados; } \\
\text { refletir sobre os conhecimentos } \\
\text { construídos; avaliar e } \\
\text { expor/divulgar/compartilhar os } \\
\text { resultados por meio de painéis } \\
\text { fotográficos, relatórios, relato de } \\
\text { experiências, seminários, grupo } \\
\text { focal, dentre outros recursos. }\end{array}$ \\
\hline
\end{tabular}

Fonte: Elaborada pelos autores (2018).

Com tal organização e desenvolvimento reduzem-se as possibilidades de o trabalho de campo ser encarado apenas como lazer ou mero passeio escolar, seja por parte do aluno e/ou até mesmo pelo 
professor. Para ir ao campo é preciso organização e planejamento das ações e dos conhecimentos a serem construídos. No campo, não basta observar o espaço geográfico, é preciso possibilitar meios para que os alunos estabeleçam as conexões, diferenciações e analogias próprias do raciocínio geográfico. Naquele momento o professor não é palestrante/transmissor de informações turísticas, mas mediador do processo de ensino-aprendizagem. No pós-campo, é preciso reflexão e avaliação sobre todas as atividades desenvolvidas e os conhecimentos construídos, reelaborando (se necessário), compartilhando e expondo/divulgando-os, num processo de síntese e veiculação das experiências vivenciadas.

Defendemos que atividades concretas e práticas como o trabalho de campo estimulam a capacidade e o desenvolvimento intelectual do indivíduo, uma vez que ao iniciarem a atividade mediada pelo professor, os estudantes têm a possibilidade de ressignificar os conteúdos que aparecem de forma abstrata nos livros didáticos e conseguem alcançar a aprendizagem para além da memorização (FARIAS, 2019a). Entendemos que por meio do trabalho de campo, os conceitos construídos em sala de aula ganham materialidade na compreensão do estudante. Por isso, longe de ser desenvolvido de qualquer modo, sem uma finalidade ou propósito educativo pré-estabelecido, sua realização precisa ser fundamentada em teorias geográficas e pedagógicas, com a sistematização e o rigor metodológico adequados ao desenvolvimento cognitivo do aluno, de modo a favorecer a aprendizagem e a aquisição de aportes teóricos e competências para a compreensão das complexas espacialidades contemporâneas.

Com base nessas fundamentações, na seção seguinte discorremos sobre as potencialidades do trabalho de campo e do método apresentado na Tabela 1, no processo de ensino-aprendizagem em Geografia, a partir da descrição e análise de um trabalho realizado no município de Pirenópolis-GO.

\section{TRABALHO DE CAMPO EM PIRENÓPOLIS-GO: UM INSTRUMENTO PODEROSO NA CONSTRUÇÃO DO CONHECIMENTO GEOGRÁFICO}

O arcabouço teórico e metodológico apresentado anteriormente alicerça nossas discussões nessa parte do trabalho, principalmente porque permite ao leitor (re)conhecer a importância e o valor pedagógico do trabalho de campo no processo de construção de conhecimentos geográficos. Além disso, possibilita compreender o desenvolvimento da pesquisa empírica apresentada e discutida nessa seção.

No desenvolvimento do trabalho de campo realizado no segundo semestre do ano 2018 em Pirenópolis-GO, com estudantes do $6^{\circ}$ ano - Anos Finais do Ensino Fundamental - de uma escola 
privada do Distrito Federal, a observação participante do professor de Geografia, também autor deste trabalho, permitiu a análise qualitativa das informações coletadas em campo. Segundo Marconi e Lakatos (2011), a observação participante é uma das técnicas mais utilizadas pelos pesquisadores qualitativos, já que permite a interação entre o investigador e o grupo estudado, diretamente do contexto ou situação específica do grupo. Além disso, essa técnica possibilita ao observador (também membro desse grupo) vivenciar o que eles (o grupo) experienciam e trabalhar dentro do sistema de referência deles.

O trabalho de campo in loco durou um final de semana e contou com a participação de 40 alunos na faixa etária entre 10 e 11 anos. Cumpre destacar que os sujeitos dessa série e idades possuem alguns aspectos que são favoráveis ao desenvolvimento do trabalho de campo, como a curiosidade, motivação, disposição e desejo pela descoberta. Assim, tal atividade torna-se interessante e atrativa ao aluno, favorecendo seu processo de aprendizagem.

Os estudantes foram acompanhados por uma equipe composta pelo professor de Geografia, orientação pedagógica, guias locais, socorrista, além dos professores de Química e Biologia, que desenvolveram atividades específicas de suas disciplinas. Embora tenham ocorrido momentos de interdisciplinaridade ou diálogo entre esses campos disciplinares durante a realização da atividade, o foco do presente artigo é destacar a contribuição/as potencialidades do trabalho de campo no processo de ensino-aprendizagem em Geografia. Cumpre destacar que, por falta de autorização da referida escola e dos familiares dos estudantes, as fotos capturadas ao longo da realização desta prática, que dariam maior impacto no texto, não puderam ser inseridas neste trabalho.

A opção pelo $6^{\circ}$ ano do Ensino Fundamental ocorreu após a análise das proposições previstas pela Base Nacional Comum Curricular (BNCC) para o segmento em questão, entre elas a "necessidade do estudo sobre os diferentes e desiguais usos do espaço, para uma tomada de consciência sobre a escala da interferência humana no planeta" (BRASIL, 2017, p. 379), e os conteúdos estudados nesta série, cujas temáticas dialogam com os fatos e fenômenos estudados em Pirenópolis-GO. Tendo essas questões como parâmetro, no trabalho em questão, cujo objetivo era o de compreender os processos de formação do espaço geográfico e das feições geomorfológicas deste município, a comparação partiu de três espaços diferentes: (i) a área de vivência dos estudantes que é Brasília-DF, um espaço urbano que surgiu do planejamento do Estado para o processo de integração territorial e desenvolvimento econômico no interior do país; (ii) a área urbana de Pirenópolis-GO, que possui um espaço produzido durante o ciclo econômico da mineração, o que a reveste com o título de cidade histórica e outra parte com características típicas de uma periferia à margem da 
circulação do capital que predomina no circuito turístico gentrificado do centro, e; (iii) o espaço rural que, no caso de Pirenópolis, apesar de estar integrado ao circuito do agronegócio regional, reveste a paisagem com aspectos da cultura tradicional goiana e do ecoturismo para atrair visitantes e dinheiro.

A atividade pré-campo foi realizada na própria escola. Nessa etapa, após o planejamento sistemático da atividade pelo professor, os estudantes receberam orientações acerca dos materiais de uso pessoal a serem utilizados durante a viagem, assim como sobre o roteiro que ia ser seguido, a utilização do caderno de campo e sua importância à aprendizagem geográfica. Na oportunidade realizou-se ainda a introdução e problematização dos assuntos que seriam discutidos nos locais visitados, como: o processo de constituição do espaço geográfico de Pirenópolis, as feições geomorfológicas do município, atividades turísticas e econômicas, cultura local e aspectos gerais da zona rural e suas relações com a zona urbana.

A etapa seguinte consistiu no desenvolvimento do trabalho de campo em si e nos procedimentos pós-campo. É importante destacar que as atividades desenvolvidas em campo foram mediadas pelo professor de Geografia, com o suporte dos guias locais. Essa fase foi dividida em quatro momentos, iniciando-se com uma caminhada pelo centro histórico da cidade para que os estudantes observassem e compreendessem os processos de formação das feições geomorfológicas do município. Conforme Godinho et al. (2011), Pirenópolis está inserido nas subunidades geomorfológicas Planalto do Alto Tocantins-Paranaíba e Depressões Intermontanas, integrantes da unidade Planalto Central. A geomorfologia local é considerada um importante atrativo turístico por conferir uma paisagem de beleza cênica e apresentar diversas cachoeiras ao longo do Rio das Almas, que compõe a Bacia Hidrográfica Tocantins-Araguaia, na porção centro-leste do município. Na ocasião, os estudantes fizeram registros no caderno de campo acerca dos processos responsáveis pela formação do relevo, como a erosão pluvial, e identificaram a relação entre a forma de relevo e o curso do rio que, no caso do município, impede qualquer tentativa de navegação. Além disso, também registraram no caderno de campo outros conhecimentos construídos, além das descobertas e curiosidades surgidas durante o trabalho de campo. Tais descobertas e aprendizados também foram socializados entre o grupo ao longo do percurso, sob a mediação do professor.

A respeito do caderno de campo, consideramos necessário enfatizar a sua elaboração e uso, uma vez que servirá como fruto do planejamento realizado pelo professor e instrumento auxiliar na mediação do conhecimento durante a atividade. Farias (2019b) destaca que o objetivo do caderno é contribuir com a orientação para as reflexões dos estudantes, ao valer-se de imagens, citações, mapas e espaços para registros a respeito dos pontos visitados. 
Não é incomum utilizar folhas em branco para que os estudantes registrem as informações do local visitado, mas entendemos que dessa forma, desperdiça-se uma rica fonte de registros guiados pelo propósito de realização do trabalho de campo. Portanto, é interessante que o caderno de campo seja construído pelo professor, até mesmo com o auxílio dos alunos durante o planejamento da atividade, uma vez que

[...] os participantes da atividade devem facilmente encontrar as principais instruções relativas à coleta de dados e informações e ao processo de observação, além de espaços adequados para registros escritos, desenhos e esquemas. [...] O caderno de campo se constitui, deste modo, um "fiel companheiro" dos participantes porque, rápida e facilmente, podem ser consultadas, em caso de dúvida, as atividades programadas e os procedimentos adotados (LOPES e PONTUSCHKA, 2009, p. 182).

Ainda sobre o trabalho de campo, faz-se importante ressaltar que os alunos mencionaram, em diversos momentos, o desgaste físico que sentiam nas caminhadas pelo centro da cidade em direção às áreas periféricas do espaço urbano (ponto que também tornou-se objeto de explanação pelo professor, relacionando-o com os conteúdos estudados) e puderam constatar como a depressão interplanáltica se apresentava na organização do sítio urbano do município e, até mesmo, nos eventuais problemas, como as situações de alagamentos das áreas mais próximas ao Rio das Almas, como a Rua do lazer, importante centro turístico do município. Nesse momento, foi inevitável a comparação com o sítio urbano de Brasília, uma vez que a principal característica da cidade é o relevo plano na maior parte das ruas e avenidas.

É necessário destacar que o trabalho de campo realizado foi fundamentado aos conteúdos de Geomorfologia e produção espacial trabalhados em sala de aula, o que facilitou a relação dos conceitos com as observações feitas em campo a exemplo de um momento no qual alguns estudantes, ao observarem uma camada de sedimentos depositados às margens do Rio das Almas, expuseram por conta própria as diferenças entre os processos de erosão e de sedimentação, demonstrando compreensão do fenômeno estudado. Ressaltamos que a teoria trabalhada tanto em sala de aula quanto em campo e o contato direto do aluno com aqueles processos geomorfológicos possibilitaram uma compreensão mais significativa dos conteúdos, e, com isso, a construção de conhecimentos geográficos. Esse é um dos pontos elementares do trabalho de campo: tornar compreensíveis e significativos os assuntos geográficos trabalhados no âmbito escolar. Essa atividade capacita os alunos a fazerem conexões dentro de um contexto espacial, para que a experiência de aprendizagem seja alcançada (MARVELL, 2013), além de oportunizar a aprendizagem em um contexto de mundo real que permite o desenvolvimento de habilidades técnicas, construção do conhecimento específico e interação social com os professores e demais colegas (FULLER, GASKIN e SCOTT, 2003). 
O segundo momento consistiu na análise do espaço urbano do município. Nessa etapa foi solicitado aos estudantes o registro das impressões a respeito do conjunto arquitetônico tombado pelo Instituto do Patrimônio Histórico e Artístico Nacional (IPHAN) e das áreas urbanas periféricas. Ao final da caminhada pelo espaço em questão, os estudantes correlacionaram suas características com as de Brasília, que é a referência de lugar que eles possuem. Demonstrando conhecimentos, ainda que com linguagem própria, os alunos ressaltaram as diferenças e semelhanças espaciais entre os lugares, destacando a forma de organização dos espaços com a circulação de capital de modo que as áreas com maior movimentação financeira tendem a obter maior atenção do poder público, como a implantação de sistemas de objetos que compõem a infraestrutura, tais como o saneamento básico, asfalto e iluminação pública.

Nesse processo, utilizamos as discussões para problematizar questões acerca do espaço urbano local e do espaço de vivência dos estudantes (o Distrito Federal), tais como a relação intrínseca do capital com a produção do espaço e o abandono do poder público, quando esse lugar apresenta baixo valor de mercado. $\mathrm{O}$ intuito foi possibilitar o desenvolvimento do pensamento crítico desses sujeitos. Sobre isso, Silva (2019, p. 12) defende que a Geografia Escolar "constitui-se como um instrumento intelectual para desvendar a realidade social, interpretar suas contradições e participar ativamente da produção socioespacial e de sua transformação". Ainda segundo a autora,

[...] os estudos geográficos servem para ler, compreender e transformar o mundo, entender a
espacialidade dos fatos e dos fenômenos, perceber o papel do espaço nas ações e relações
sociais ou nas práticas cotidianas, compreender a realidade à luz de sua dimensão espacial,
desenvolver novos modos de pensar, desenvolver o intelecto e o pensamento crítico, construir
aportes teóricos que contribuam na construção e no exercício da cidadania, desvelar as
contradições da sociedade contemporânea, ampliar a consciência sobre as práticas espaciais
e compreender as relações hegemônicas e os modos de intervenção nelas (SILVA, 2019, p.
12).

O trabalho de campo tem condições para contemplar tais perspectivas formativas e contribuir com a transformação de conceitos cotidianos em conceitos científicos, sistematizados a partir da mediação didática realizada pelo professor. Tendo por referência essa questão, enfatizamos mais uma vez a importância da realização do trabalho de campo como método de mediação do conhecimento, seguindo o objetivo que se deseja alcançar.

O estudo do espaço rural contemplou o terceiro momento da atividade. Embora a agropecuária não seja o forte do município, a região possui fazendas que exploram o turismo rural como complemento financeiro à produção destinada aos mercados. Nesse caso, os estudantes visitaram a Fazenda Babilônia, uma propriedade tombada pelo IPHAN como patrimônio nacional que conserva o casarão construído no século XVIII. Nessa etapa eles puderam assimilar a ocupação do espaço com 
as feições geomorfológicas locais e constataram a relação entre o relevo e a economia, uma vez que a agricultura comercial não era praticada em função das dificuldades em inserir o maquinário moderno típico do agronegócio, de forma que a área é ocupada pela pecuária leiteira de forma extensiva. Apesar disso, os estudantes analisaram aspectos da cultura imaterial como a culinária goiana e degustaram um café colonial com pratos típicos que remontam à época dos tropeiros, responsáveis por abastecer a região durante o ciclo econômico da mineração. Importante ressaltar que, apesar de não ser objeto de estudo do $6^{\circ}$ ano, nesse momento também foi abordada a produção do espaço geográfico brasileiro e como os ciclos econômicos colaboraram com o processo de interiorização e ocupação do território, já que se relaciona com as temáticas trabalhadas em campo e em razão de ter despertado a curiosidade dos alunos a partir da observação da paisagem local e da relação homem-natureza.

Nessa parte do trabalho destacamos novamente a importância do caderno de campo no desenvolvimento da autonomia do aluno ao registrar e analisar os elementos presentes e perceptíveis na paisagem, o espaço dado pelo professor para o diálogo, a interação entre os colegas e entre o sujeito e o objeto de estudo, e para a reflexão sobre os fatos/fenômenos observados. O caderno de campo não foi um simples bloco de papel em branco para ser preenchido segundo os critérios dos estudantes. Esse material foi elaborado com base no planejamento do professor de Geografia, pensando em sistematizar as informações problematizadas durante toda a atividade. Tal situação pode ser observada na imagem 1, que destaca uma das perguntas utilizadas no caderno de campo, com o objetivo de localização no espaço, bem como de análise da geomorfologia local.

Notamos que os alunos puderam perceber que o município está próximo de duas grandes metrópoles do Centro-Oeste (Brasília e Goiânia), o que dinamiza o turismo local. Ademais, faz-se necessário ressaltar que o óbvio precisa ser dito, uma vez que por se tratar de uma atividade realizada com estudantes do $6^{\circ}$ ano, as coisas mais simples precisam ser esclarecidas, ou seja, o reconhecimento dos fenômenos espaciais a partir da leitura da paisagem presente (FARIAS, 2019b).

Como ilustração desse processo, uma aluna perguntou ao professor se ela estava no estado de Minas Gerais por haver pão de queijo no café da manhã. Um mapa de localização espacial, por mais simples que seja, possibilitou trabalhar ainda com a escala geográfica, para que fosse possível identificar a posição do município de Pirenópolis em relação ao estado de Goiás e ao Distrito Federal.

Cumpre destacar que os alunos registraram suas impressões, tiraram dúvidas e expuseram suas curiosidades e descobertas em cada ponto de exploração ao longo do percurso, demonstrando 
interesse pelos assuntos abordados e construção de conhecimentos geográficos, principalmente relacionados à produção espacial e às questões geomorfológicas do município de Pirenópolis-GO.

Ao término do trabalho de campo e já no espaço da sala de aula, desenvolveu-se a atividade pós-campo. Esta consistiu na realização de um grupo focal, no qual os estudantes, após a sistematização das informações e dos dados registrados no caderno de campo durante a saída, relataram e compartilharam as experiências vivenciadas. O grupo focal é uma estratégia metodológica que, segundo Gatti (2012), possibilita a discussão entre um grupo de pessoas, com foco em um tema específico, vivenciado por todos. Trata-se de uma atividade coletiva, em que os sujeitos discutem e comentam determinado assunto tido como objeto de estudo, trocam/compartilham suas experiências, interagem. De acordo com essa autora, "o grupo focal permite fazer emergir uma multiplicidade de pontos de vista e processos [...] pelo próprio contexto de interação criado, permitindo a captação de significados que, com outros meios, poderiam ser difíceis de se manifestar" (GATTI, 2012, p. 9).

FIGURA 1 - PERGUNTA UTILIZADA NO CADERNO DE CAMPO.



Figura 01: Localização do municipio de Pirenópolis no Estado de Goiás, ressaltando sua localização estratégica no que se refere ao fluxo/circulação de pessoas.

SOUZA, Fernando Estevam de; LIMA, Cláudia Valéria de. Análise dos Condicionantes Físicos em Bacias Hidrográficas do Municipio de Pirenópolis (GO) e Suas Relações Com o Turismo. Goiânia, Goiás, 2011.

O mapa acima revela a localização geográfica de Pirenópolis. A partir da análise, relate como a localização e geomorfologia do município colaboram para a prática econômica do Turismo.

Fonte: Caderno de campo utilizado na experiência pedagógica desenvolvida, 2018. 
Nessa etapa e no grupo de discussão os alunos também expuseram como os conteúdos abordados em sala de aula eram visíveis e compreensíveis no campo e como a vivência esclareceu processos que até então eram considerados abstratos/sincréticos e incompreensíveis, a exemplo da modelagem do relevo a partir da erosão e deposição de sedimentos, dentre outras questões que envolvem a (re)produção espacial de Pirenópolis-GO, destacando especialmente a paisagem urbana, que ainda preserva parte da arquitetura fundada no tempo do ciclo econômico da mineração.

Por fim, notou-se que aqueles estudantes construíram, de modo mais inteligível e significativo, os conhecimentos geográficos previamente estabelecidos. Esta constatação ocorreu tanto durante a realização do trabalho de campo, a partir da fala dos estudantes, como no pós-campo com o grupo focal/de discussão, quando evidenciou-se a compreensão/apropriação dos conteúdos estudados.

Pela atividade desenvolvida compreende-se que a apropriação de um método que assegure o desenvolvimento pedagógico do trabalho de campo e de aportes teóricos que favoreçam a compreensão da(s) espacialidade(s) dos fatos/fenômenos vivenciados contribui para a construção de conhecimentos geográficos, e nisso, para o desenvolvimento cognitivo e a formação do pensamento crítico do indivíduo, como constatado ao longo deste trabalho. Essa prática, que não consistiu em um simples passeio, recreação, lazer, excursão ou mera saída escolar, viabilizou e facilitou o processo de aprendizagem geográfica.

\section{CONSIDERAÇÕES FINAIS}

À luz das questões abordadas entende-se que o trabalho de campo é uma atividade preciosa/poderosa e que pode ser bem aproveitada no âmbito escolar. Para isso, o reconhecimento de sua potencialidade no processo de ensino-aprendizagem é o primeiro passo. A compreensão de que as atividades concretas e práticas, sobretudo no local onde os fenômenos ocorrem, promovem o desenvolvimento intelectual do indivíduo, constitui a segunda etapa. O conhecimento de que uma atividade prática vivenciada em situações concretas, como o trabalho de campo, apenas será significativa se propiciar a atividade cognitiva do estudante, é a terceira fase. As demais etapas demandam compreender que a reflexão, o diálogo, a interação, a descoberta, a experimentação, a autonomia do indivíduo, o envolvimento com o objeto e com os demais sujeitos partícipes da atividade, e a mediação do professor são pilares essenciais nos processos de ensinar e aprender Geografia, principalmente na Educação Básica. 
É fato que muitas escolas ainda consideram o trabalho de campo como um passeio ou atividade recreativa, cujo desenvolvimento não promove a construção do conhecimento geográfico, tampouco oportuniza o desenvolvimento cognoscitivo do aluno. Em sua maioria, desenvolvem-se por meio de práticas com princípios tradicionais, onde o professor verbaliza, descreve o fato/fenômeno, transmitindo as informações e, ao aluno cabe apenas internalizá-las. Torna-se necessário romper com essa prática tradicional de ensino e de aprendizagem e considerar o aluno como um sujeito. Além disso, espaço de diálogo, reflexão, experimentos, atividades físicas e mentais devem ser oportunizadas nas aulas de Geografia. De igual modo, o trabalho de campo precisa ser compreendido para além da empiria, dado que possui método e fundamentação teórica para seu desenvolvimento.

Cumpre destacar que mesmo frente às mais variadas possibilidades que as tecnologias digitais trazem à educação e à aprendizagem geográfica, especialmente ao propiciar a descoberta e o conhecimento acerca de diferentes espaços geográficos, o trabalho de campo ainda é um recurso insubstituível por permitir uma aprendizagem significativa, com base na vivência, na relação com o outro e com o objeto estudado, viabilizando uma (re)leitura geográfica propícia à construção do conhecimento e da cidadania.

Dado o exposto, destacamos que não é nossa pretensão tornar esse trabalho uma receita pronta para ser feita e reproduzida na prática escolar. Longe disso, nosso intuito enquanto professores da Educação Básica foi compartilhar uma experiência sistematicamente desenvolvida, que, partindo de uma tessitura teórica sólida e da apropriação de um método, pudesse possibilitar a reflexão sobre como aprender Geografia a partir do desenvolvimento adequado do trabalho de campo. Mas, àqueles que se apropriarem do método utilizado no trabalho de campo em questão, solicita-se a adequação às especificidades do contexto escolar, aos materiais disponíveis, às demandas intrínsecas aos sujeitos e aos próprios saberes docentes, que são essenciais ao alcance da aprendizagem geográfica por meio dessa metodologia. Ademais, ressalta-se a possibilidade de realizar uma atividade metodologicamente sistematizada com alunos da Educação Básica, de modo que diferentes momentos do fazer docente se constituam em aprendizagem significativa para os discentes. 


\section{REFERÊNCIAS}

AMOS, R., \& REISS, M. The benefits of residential fieldwork for school science: Insights from a five-year initiative for inner-city students in the UK. In: International Journal of Science Education. London (UK), 34(4), 485-511, 2012.

BRASIL. Ministério da Educação. Base Nacional Comum Curricular: educação é a base. BrasíliaDF, 2017. Disponível em: <http://basenacionalcomum.mec.gov.br/wpcontent/uploads/2018/12/BNCC_19dez2018_site.pdf>. Acesso em 20 jan. 2020.

CALLAI, H. C. A formação do profissional da Geografia. Ijuí: Unijuí, 2013.

A Geografia ensinada: os desafios de uma educação geográfica. In: Formação de professores: conteúdos e metodologias no ensino de Geografia. Goiânia: NEPEG, 2010.

CARVALHO SOBRINHO, H. A categoria lugar na construção dos conhecimentos geográficos: análise a partir da prática pedagógica do professor de Geografia em Formosa - Goiás. Dissertação de Mestrado, Brasília - DF, Universidade de Brasília, 2016.

CAStrogiovanni, A. C (Org.). Ensino de Geografia: práticas e textualizações no cotidiano. Porto Alegre: Mediação, 2000.

CAVALCANTI, L. S. Geografia, escola e construção de conhecimentos. Papirus Editora, 1998.

O ensino de Geografia na escola. Campinas, SP: Papirus, 2012a.

A Geografia escolar e a cidade: ensaios sobre o ensino de Geografia para a vida urbana cotidiana. $3^{\text {a }}$ ed. Campinas, SP: Papirus, 2012b.

DAMIANI, A. L. A geografia e a construção da cidadania. In: CARLOS, A. F. A. (org.). Novos caminhos da geografia. $9^{a}$ ed. São Paulo: Contexto. 2015.

FARIAS, R. C. O trabalho de campo na perspectiva de ensino de geografia: uma revisão crítica a partir do cenário internacional. Revista Brasileira de Educação em Geografia, v. 9, n. 17, p. 181198, 2019a.

- Trabalho de campo em unidade territorial de aprendizagem: possibilidade para o ensino de cidade na geografia escolar. 2019. 160 f., il. Dissertação (Mestrado em Geografia) Universidade de Brasília, Brasília, 2019b.

FIALHO, L. M. F; DOS SANTOS MACHADO, C. J; DE SALES, J. Á. M. As correntes do pensamento geográfico e a Geografia ensinada no ensino fundamental: objetivos, objeto de estudo e a formação dos conceitos geográficos. Educação em Foco, v. 17, n. 23, p. 203-224, 2014.

FULLER, I. C., GASKIN, S., \& SCOTT I. Student perceptions of geography and environmental science fieldwork in the light of restricted access to the field, caused by foot and mouth disease in the UK in 2001. In: Journal of Geography in Higher Education. London (UK), 27, 79-102, 2003.

GATTI, Bernadete Angelina. Grupo focal na pesquisa em ciências sociais e humanas. Brasília: Liber Livro Editora, 2012.

\begin{tabular}{lll}
\hline Farias e Silva, 2021 & ISSN 2594-9616 & 148
\end{tabular}


GODINHO, R. G. et al. Geomorfologia e Turismo no município de Pirenópolis (GO). Caminhos de Geografia, v. 12, n. 37, 2011.

GONZÁLES, X. M. S. Didáctica de la Geografía: problemas sociales y conocimiento del medio. Barcelona: Ediciones del Serbal, 1999.

KENT, M., GILBERTSON, D. D., \& HUNT, C. O. Fieldwork in geography teaching: A critical review of the literature and approaches. In: Journal of geography in higher education. London (UK), 21(3), 313-332, 1997.

LOPES, Claudivan Sanches; PONTUSCHKA, Nídia Nacib. Estudo do meio: teoria e prática. Geografia (Londrina), v. 18, n. 2, p. 173-191, 2009.

MARCONI, M. A; LAKATOS, E. M. Metodologia científica. 6ª ed. São Paulo: Atlas, 2011.

MARVELL, A., SIMM, D., SCHAAF, R., \& HARPER, R. Students as scholars: evaluating studentled learning and teaching during fieldwork. In: Journal of Geography in Higher Education. London (UK), 37(4), 547-566, 2013.

NEVES, K. F. T. V. Os trabalhos de campo no ensino da geografia: reflexões sobre a prática docente na educação básica. Editus, Editora da UESC, 2015.

PONTUSCHKA, N. N. Estudo do meio, interdisciplinaridade, ação pedagógica. In: ENCONTRO NACIONAL DE GEÓGRAFOS, 13, 2004. Anais... Goiânia, GO, 2004.

SANTOS, M. O espaço do cidadão. Edusp, 2007.

SILVA, A. S. Afinal, para quem serve a reforma do Ensino Médio? Signos Geográficos, GoiâniaGO, v.1, 2019. Disponível em: <https://www.revistas.ufg.br/signos/article/view/59937/34080>. Acesso em 20 jan. 2020.

SMITH, F. M. Euro-commentary: Encountering Europe Through Fieldwork. In: European Urban and Regional Studies. London (UK), 13(1), 77-82, 2006. 